\title{
A TECITURA DO SILÊNCIO NA NARRATIVA DE GRACE PALEY
}

REFERẼNCAS BIBUOGRÁFICAS

BAKHTIN, M.M. The Dialogic Imogination: Four Essoys. Ed. Michoel Halquist. Austin: University of Texos Press, 1981. BRADBURY, Malcolm. Neoredist fiction. Columbio history of the Americon Novel. New York: Columbia University Press, 1991.

CROMTHER Hol. Clinging the the Rock. A Hed R, Hol. Clinging to the Rock. A Aovelist's Chaices in the New Mediociocy.
Durhom: Duke University Press, 1991, pp. B3-98.

DECURTIS, Anthony. An Outsider in this Sociely: An Interview with Don Delillo.
Lentricchio, Fronk ed. Introducing Don Delillo. Durham: Duke University Press, 1991, pp. 43-66.

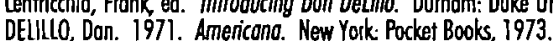

. End Zone. 1972. New York: Penguin, 1986.

- Moo ll. New York. Penouin 1991 .

The Nomes 1982 . Mew Yort Vintoge 1989

Running Dog. New York Koopt Vintoge

Wunning Dog. New York: Knopt, 1978.

FOSTER, Dennis. Alphabetic Pleasures: The Names. Lentricchia, Fronk, ed. Introducing Don Delillo. Durham: Duke Universily Press, 1991, 157-173.

GUARESCHI, Pedrinho, et olii. Comunicosdo e Controle Sociol. Petropolis: Vozes, 1991

JAMESON, Frederic. Review of The Names. Minnesoto Review, no. 22, pp. 116-122, Spring 1984

JOHNSTON, John. Generic Difficulfies in the Novels of Dan Delillo. Critique, vol. 30, no. 4, pp. 261-275, Summer 1989.

KELLNER, Douglas. Jean Boudillord. From Morism to Postimodernism and Beyond. Sianford: Stonford University Press, 1989.

LECIAR, Tom. An Interview with Don Delillo. Contempoorory Lterature, vol. 23, no. 1, pp. 19-31, Winter 1982.

-. In the Loop: Don Delillo ond the Systems Novel. Urbana: Univensity of Illinais Press, 1987.

LENTRICCHIA, Fronk, ed. Introducing Don Delillo. Durhom: Duke Universiyy Press, 1991.

MCCUURE, John. Postmodern Romance: Don Deillo and the Age of Conspiracy.

Lentricchio, Fronk, ed. Introducing Don Delillo. Durham: Duke University Press, pp. 99-115.

MORRIS, Motthew. Murdering Words: Longuoge in Adion in Don Delillo's The Names. Contemporary Literoture, vol. 30, no. 1, pp.

OSTEEN, Mark, Agoinst the End: Asceticism and Apolalypse in Don Delillo's End Zone. Papers on Longuoge ond Literoture, vol. 26, POSTER Mo. 1, pp. 143-163, Winter 1990.

erm of Sell-Constitution. Fouccoulf ond the Critique of Institutions. Ed. John Caputo and Mark Yount. University Park: Penn Stote University Press, 1993.

SALITMAN, Arthur. The Figure in the Stratic: White Noise. Modern Fiction Strdies, vol. 40, no. 4, po 807-826 Winter 1994.

SCANLAN, Morgoret. Writers Among Ierrorists: Don Delililo's Mao Il and the Rushdie Affair. Modem Fiction Studies, vol, 40, no. 2 SHAPIRO, Mp. 229-251, Summer 1994.

WILLIAMS, Raymond. Problems in Moteriolism ond Culture: Selected Essays. London: Verso, 1980.
Suely Maria de Paula e Silva Lobo

$P U C-M G$

\begin{abstract}
Ouve-me, ouve meu silêncio. $O$ que falo nunca é o que falo e sim outra coisa. ... Capta essa outra coisa de que na verdade falo porque eu mesma nāo posso.
\end{abstract}

Clarice Lispector (Água viva)

\section{RESUMO}

Este trabalho procura demonstrar a maneira como a escrita de Grace Paley, autora americana contemporânea, joga com o silêncio e o não-dito para denunciar e desconstruir falsos valores sobre os quais se estruturam determinados construtos sociais.

PALAVRAS-CHAVE:

Grace Paley, silêncio, máscara, voz.

Falemos, aqui, de silêncio, pois esse é um modo eficaz de tentar ouvilo, de tentar compreender, através de suas múltiplas facetas, a potencialidade de expressão que nele subjaz.

E ninguém melhor que Grace Paley para deixar-nos vislumbrar essa riqueza de linguagem. Paley, com sua escrita fragmentada, descontínua e que, freqüentemente, privilegia vozes intermitentes e ambíguas em detrimento de outras, fluentes e claras, reina, poderosa, nesse campo de expressão. Quatro 
curtíssimos contos de sua autoria aqui analisados deixarão perceber como, em Paley, a mistura do poético e do grotesco encontra sua expressividade máxima nos momentos de silêncio.

Já se pode perceber, então, que o silêncio de que falamos não é sinônimo de vazio e de ausência. É, ao contrário, uma fala rica de sentido e parte integrante e significativa da estrutura narrativa e dramática do texto. Bakhtin fala do silêncio como o momento em que a palavra é removida do diálogo, fato que gera, porém, em dadas circunstâncias, uma tal força de expressão que acaba por criar um espaço de significação que ele chama de "logosfera".

E por que motivos é a palavra, às vezes, removida do diálogo? Em certas situações, isso se dá como uma forma de oposição à fala; em outras, como uma complementação a ela; em outras, ainda, como ênfase na revelação de uma impossibilidade.

Parece oportuno, neste ponto, detalharmos os aspectos que caracterizam os efeitos vários, as múltiplas formas de expressão produzidas pela voz que se ausenta.

Ao analisar a intrincada relação que toma corpo entre o que se revela e o que se oculta, entre o dito e o não-dito, Kierkegaard destaca o silêncio como um dos dois extremos de um jogo binário com a fala e identifica nele quatro tipos básicos de significação: silêncio cômico, silêncio enganador, silêncio heróico e silêncio demoníaco?

Ainda que não seja nosso propósito basearmo-nos, estritamente, nessa classificação, ela nos parece iluminadora e pertinente como referencial analítico. Por tal motivo, valerá a pena esclarecer alguns de seus pontos.

O silêncio cômico é a forma sobre a qual é, geralmente, construída a ação de comédias de costumes, comédias de situação e textos similares, nos quais entram em jogo identidades trocadas e falas de duplo sentido, à moda, digamos, de Sheridan, Wilde ou Martins Pena. As eventuais perdas geradas pelo silenciar intencional são repostas ao final, quando o silêncio é rompido por revelações que são trazidas à tona e revertidas em ganho permanente para os participantes, que, hollywoodianamente, viverão felizes para sempre.

O silêncio enganador traz consigo o travo amargo da traição, o que

1. BAKHTIN, 1986.

2. KIERKEGARD, 1983. torna a conciliação final impossível, uma vez que, do ponto de vista de Kierkegaard, o que é gerado no equívoco ramifica-se em desequilíbrio e desencontro.

O silêncio heróico tem em torno de si uma leve marca do ilusório, pois aquele que se cala o faz por pensar poder, assim, proteger ou salvar alguém. Não se cala apenas. Na verdade, quase religiosamente, guarda silêncio.

O silêncio demoníaco é o mais cruel, pois nele nenhuma força externa tolhe o sujeito. Ele pode falar, mas, simplesmente, não o faz, recusando-se a traduzir sua interioridade em exterioridade, numa forma de resistência que, para Kierkegaard, constitui-se como permanente obstáculo a uma atitude ética frente ao mundo.

Se considerarmos a obra de Paley em sua totalidade, veremos que a autora se movimenta de modo natural e competente por esses diversos meandros do silêncio. Resultados cômicos, tragicômicos, heróicos ou trágicos são conseguidos, em várias de suas narrativas, por meio de construções que se podem descrever a partir da classificação de Kierkegaard.

Nos contos selecionados, no entanto, não são essas as formas de silêncio mais evidentes: aparecem, aqui e ali, como um sinal da multiplicidade de recursos que a autora tem a seu dispor. É o caso, por exemplo, do silenciar demoníaco do marido em relação à esposa em "Mother", ou do silenciar heróico do inventor-artista em "This is a story about my friend George, the toy inventor", que, na condição de empregado de uma empresa, ao concordar com à rejeição imposta a seu trabalho, nada mais faz do que se calar para proteger a si próprio e à família.

Embora significativa, essa relação binária entre silêncio e fala, todavia, não nos mostra Paley em sua melhor performance. É na condição de complementação à palavra que a trama do silêncio é tecida pela autora e por ela transformada em algo que não será o contrário da fala, mas seu mais fiel escudeiro na tarefa de explorar possibilidades de expressão.

É de dentro dessa perspectiva que advém a força maior desse recurso, usado como substituto de reações violentas, ou outras, indesejadas na caracterização de certas personagens, ou como sinal de adaptação delas ao sistema vigente.

3. PALEY, 1985. p.111.

4. PALEY, 1985. . .147. 
O título "In this country, but in another language, my aunt refuses to marry the men everyone wants her to" , longo demais em qualquer texto, mostrase, aqui, especialmente exagerado, a ponto de criar, por si so, um efeito cômico. O mesmo ocorre em relação à diversidade de personagens, não apenas citadas, mas a quem também é dada a palavra. São elas a própria narradora, sua tia, a avó, o pai e a mãe. Excesso que obriga o leitor de primeira vez a reler parágrafos, a voltar ao texto para tentar colocar ordem na algaravia: quem fala agora? Com quem fala? E para, então, perceber que a substância do que dizem não se encontra explicitada no diálogo apenas, mas terá que ser buscada, também, nos silêncios que se fazem entre as falas e nas próprias falas.

Assim é que, pelo que se fala, fica-se informado sobre o estado de saúde da avó, a vida difícil que tivera, o filho que perdera, o amor que dedica aos netos, sua preocupação pelo futuro da filha. Também se toma conhecimento dos laços existentes nessa família, do envolvimento que une seus componentes e do efeito que passado, presente e futuro parecem ter sobre cada um deles.

Se por um lado, porém, obtemos informações que nos permitem compor um quadro representativo de uma realidade familiar, por outro temos uma área de silêncio que se torna, pouco a pouco, mais reveladora e eloqüente do que a fala que se pode ouvir.

Na composição dessa linguagem, a figura retórica do understatement é a mola propulsora que coloca em relevo muito do que, sem esse recurso, passaria despercebido. Considerando que o understatement é a arte de narrar ou descrever sem que se revelem especificidades relacionadas a fatos ou sentimentos, diríamos que essa é uma arte do implícito, através da qual se cria, ao se omitirem detalhes, uma tensão emocional de maior efeito do que se o explícito tivesse sido apresentado.

Assim, todo um relato de perda e luta é, indiretamente, passado ao leitor quando a tia refere-se à avo, dizendo:

... You wouldn't believe what a life she had. It wasn't life. It was torture.

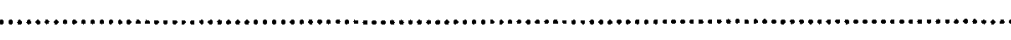

(...) Ach, what she saw!

5. PALYY, 1985. p.147. Em português: "Neste poís, mos em outra lingua, minha tia se recusa a casor-se com os hamens com os quois todo mundo quer que elo se case."

6. PALFY, 1985. p.107. Em português: "Você nōo acceditorio no vida que ela teve. Näo foi uma vida. Foi uma torturo. (...) Ah! 0 que elo viu!"
Ao não descrever que vida fora a da avó e que coisas havia ela visto, a personagem cria uma linguagem silenciosa que dialoga com a imaginação criadora do leitor, que, feito parceiro, saberá como preencher as lacunas geradas pelo não-dito para reconstruir a história de uma vida e de uma luta da qual ele pouco sabe em termos factuais, mas cuja dor e frustração é capaz de reconhecer.

Se, em relação à avó, o não-dito é o canal de informação que o leitor tem a seu dispor, o mesmo não ocorre em relação à tia, de quem ele poderá saber mais, por meios menos indiretos.

Para deixar mais clara essa observação, reportemo-nos à fala da avó quando diz não conseguir dormir à noite preocupada com o fato de a filha não estar aproveitando a vida: You have no life. ${ }^{7}$ O silêncio permeia essa afirmativa no que ela contém de realmente significativo: o que será "vida" para a avó? Em que medida a filha não preenche o modelo daquilo que a avó convencionou chamar "vida"? (A avó parece acusá-la disso e não apenas constatar um fato). Como essa não-vida poderá ser revertida em "vida"?

O leitor não terá muito trabalho para encontrar as respostas, já que o título lhe dissera desde o início: "In this country, but in another language, my aunt refuses to marry the men everyone wants her to".

O silêncio do texto é aqui rompido por uma informação passada ao leitor pela fala do título, que, se ouvida, revela, tanto a posição tradicional da avó, quanto a recusa desse tradicionalismo, implícita na atitude da tia. A avó cobra da filha a manutenção do "status quo" familiar dentro de uma determinada ordem que considera que a mulher s 6 afirma sua identidade através da figura de um marido. Sem ele, you have no life, parece estar dizendo a avó. A tia, no entanto, refuses to marry the men everyone wants her to $\mathrm{e}$, assim, foge do padrão esperado, afirma a existência de uma visão que é sua e que contraria os modelos tradicionais.

Título tagarela e indiscreto que conta segredos e problemas da família e permite ao leitor recompor um diálogo em que uma voz, vinda do co-texto, quebra um silêncio, perturba um dito, esclarece um não-dito e preenche lacunas.

O título diz mais. Revela desde logo a origem estrangeira da família (confirmada mais tarde pelo nome do filho que morre numa passeata de protesto) e explica que a recusa da tia se dá em uma língua que não aquela ali falada.

É aí, no entanto, que esse título, que até então funcionara como fala 
ao romper um silêncio e esclarecer o leitor, destrói essa cumplicidade e deixao outra vez em um espaço lacunar. Que língua é essa a que se refere? Trata-se de idioma falado em um país ou de língua falada por uma mulher-terra-estranha em um país que não é o seu?

Que grande área de silêncio se faz aqui com a inserção de in another language em título tão falante! Ainda assim, como já dissemos, é área que se forma como complementação à fala e não como seu oposto, uma vez que permite interpretações que poderão se constituir como diálogos com o dito. $O$ que temos aqui, portanto, não é apenas uma área vazia, porém muito mais, temos uma ária prenhe de harmonias em suspensão, de sentidos em latência. seu final:

Que voz virá, agora, em socorro do leitor? Talvez, a voz do texto no

... Sonia tell me no or yes. Do you have a life?

Ha! she said. If you really want to know, read Dostoievsky. ${ }^{\circ}$

E essa voz, contudo, está perpassada pelo silêncio contido na referência a Dostoievsky. O que estaria ela dizendo? Possivelmente, "Só em um mundo de paixão e emoções como se vê em Dostoievsky se vive. Na mornidão do dia-a-dia de todos nós, ninguém tem, verdadeiramente, uma vida". Ou, talvez: "Troco as certezas da tepidez do ninho pelas incertas graças da paixão; enquanto não me deixar fechar no esquema proposto, estarei preservando a possibilidade de ter minha própria biografia".

O que essa voz quer dizer não fica verdadeiramente esclarecido, mas há nela, de qualquer modo, um eixo dostoievskiano de reconhecimento da imperfeição da condição humana e do desejo ardente de alguma forma de liberdade. Um tom que, talvez, esteja mesmo sugerindo que, se se vive em um mundo que exige acomodação e adaptações, então melhor seria não se entregar à loucura de expressar a dor e o desejo, mas, sim, curvar-se à morna compulsão de agradar, como condição básica de sobrevivência. Laugh! '?

A avó já se perdeu deste mundo, já se sente para além dele, tanto é que se espanta ao emergir viva da longa noite, a cada manhã. Por isso pergunta

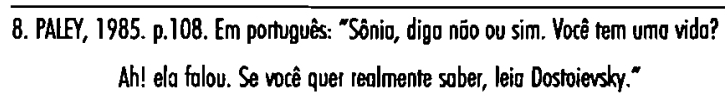

por que riem. Mas a tia sabe que ainda terão que continuar, todos silentes quanto à própria frustração, dor ou paixão. Por tal razão, é sua a palavra final no texto. Ouvimo-la dizer: Laugh! Reação que não é fala nem silêncio, mas que participa da natureza de ambos por conter a sonoridade de uma e o não-dizer-dizendo de outro. Todos eles sobreviventes - como em geral o são as personagens de Grace Paley -, movimentando-se por entre destroços das ilusões e combatendo a desesperança com as forças buscadas no dia-a-dia:

$$
\text { ... my aunt said, Laugh! }{ }^{10}
$$

No silêncio embutido em Laugh!, vê-se a máscara das personagens preparando-se para encarar os rostos umas das outras. E vê-se a máscara da escrita ocultando a face da palavra para, assim, revelá-la melhor.

Em "Mother", o silêncio advém tanto do uso de determinadas palavras como dos vazios que se fazem entre uma sentença e outra, ou entre um parágrafo e outro. É dessa maneira que o advérbio naturally" atinge o leitor com intensidade. Atinge-o pelo que nele se encontra implícito, pelo que registra e traz de volta à mente desse leitor. E o que registra ele?

Na verdade, um repertório calcado sobre traços básicos que retratam formas de incomunicabilidade interpessoal e familiar: uma filha que se vê constantemente envolvida por questões de ordem particular entre as quais não se encaixa a presença da mãe; a mãe que, por medo do já-visto e do já-vivido, não consegue entender a busca individual empreendida pela filha, incompreensão que se explicita no comentário: You run around senselessly. What will become of you? ${ }^{12}$

Quando a isso se segue o registro súbito, inesperado, da morte da mãe - Then she died ${ }^{13}$-, o advérbio naturally, que aparece em seguida, reveste-se de toques de tragicidade. Em nível do dito, ele anuncia uma busca que atravessará uma vida; o não-dito lembra ao leitor a inutilidade dessa busca.

O espaço que separa cada um desses momentos é, graficamente, pequeno, porém, semanticamente, imenso. Quase tão grande quanto a perda de que fala. Quase tão longo quanto o longo trecho que se faria necessário para

10. PALY, 1985. p.108. Em português: "... minho tia disse: Ria!"

11. PALYY, 1985. p.112.

12. PALEY, 1985. p.112. Em português: "Você ondo em círculos, sem sentido. 0 quê será de você na vida?"

13. PALFY, 1985. p. 112 . 
descrever, em palavras adequadas e reveladoras, o que poderia ter sido e não foi e o que se buscará em vão dali em diante.

Volta-se no tempo. A voz da filha descreve mãe e pai juntos, acomodados em confortáveis cadeiras de couro, ouvindo Mozart e Bach. Criase um quadro idílico. Pensa-se nos dois em contato com a rara serenidade da música de Mozart, mesclada em muitos de seus momentos a uma inspiração apaixonada e trágica e, ainda, com o espírito de fé procedente da música de Bach, às vezes banhada pela leveza da harmonia das manifestações do cotidiano da vida. Momento raro de encontro.

Só a música quebra o silêncio.

E, com essa constatação, desfaz-se subitamente, nesse contexto, a idéia de harmonia e encontro: só a música fala, o homem e a mulher, não:

She said to him, Talk to me a little. We don't talk so much anymore. I'm tired, he said (...) Listen to the music, he said. ${ }^{14}$

O quadro idílico se rompe, pois o casal faz contato com a música mas não entra em sintonia entre si.

Uma vez mais, ouve-se o silêncio - transformado em diálogo entre a filha e o leitor. Silêncio/diálogo que fala de uma relação da qual a palavra foi alijada, de uma voz que não aflorou, de uma perda gerada pelo que não se pôde ouvir.

É esclarecedor introduzir, aqui, a distinção que Bakhtin estabelece entre "quietude" e "silêncio" 15 . Para ele, o ponto comum entre os dois conceitos é o fato de ambos pertencerem à dimensão de uma ausência. Mas a semelhança termina aí, uma vez que a "quietude" indicaria a ausência do som, e o "silêncio", a ausência da palavra. A quebra da "quietude" dá-se, portanto, diante de uma percepção que poderá ser puramente mecânica, fisiológica: alguma coisa produz um som (que é captado pelo ouvido) e perturba a "quietude". Mas o "silêncio" só se quebra pela palavra.

Isso implica, por um lado, a idéia de que o silêncio só existiria no mundo dos humanos - já que para rompê-lo ou mantê-lo é preciso que alguém

14. PALEY, 1985. p. 112. Em português: "Elo disse a ele: Converse comigo um pouquinho. Nós jó nõo conversomos muito. Estou consodo, ele disse. Escute o músico, ele disse."

15. BAXHTIN, 1986. fale, ou não. Por outro, implica a questão da "inteligibilidade", noção que Bakhtin relaciona à palavra mas não ao som (se o considerarmos como aquilo que é produzido por "alguma coisa", e não por "alguma palavra").

Nesse sentido, o "silêncio está revestido das características da palavra, o que lhe confere a qualidade de som inteligíviel e lhe permite constituir-se na categoria da estrutura chamada (como já se disse) de logosfera.

Desse ponto de vista, pode-se considerar que a música ouvida pelo casal encontra-se no campo do som que rompe uma quietude, mas não no da fala que rompe um silêncio.

She said to him, Talk to me a little. We don't talk so much anymore. I'm tired, he said (...) Listen to the music (...) ${ }^{16}$.

Em troca da palavra negada, é oferecido o som da música. O silêncio permanece falando de ilusões que se foram, de solidão, egoísmo, desesperança. Permanece. Até cristalizar-se, definitivo, irrevogável, na palavra final: Then she died. ${ }^{7}$ Então, cala-se.

Em "A man told me the story of his life"18 $\mathrm{e}$ "This is a story about my friend George, the toy inventor"'", o silêncio permeia, não mais a relação em nível puramente interpessoal, mas a relação entre as personagens e o sistema.

Vicente, personagem do primeiro conto, e George, do segundo, não ousam contestar os papéis que lhes são designados e, assim, estabelecem, com o meio social, um diálogo pontuado pelo silêncio.

Vicente dialoga com a escola, a qual se recusa a deixá-lo ouvir seu próprio desejo, fazendo com que se sobreponha a esse desejo a voz do paternalismo, do autoritarismo, do cientificismo. A personagem não consegue ter sua fala ouvida pela instituição e rende-se a isso ao dizer: ... But perhaps you're right. You're the teacher. ${ }^{20}$

Dessa maneira, ao mesmo tempo que emite um discurso de aceitação do que lhe é destinado como participante do grupo social, a personagem se cala
16. PALEY, 1985. p.112.
17. PALEY, 1985. p.112. Em português: "Entĩo elo morrev."
18. PAIEY, 1985. p.129.
19. PALEY, 1985. p.147.
20. PALEY, 1985. p.128. Em português: "(...) Mas talvez o senhor estejo com a razó0. 0 senhor é o professor." 
sobre o que verdadeiramente deseja, transformando sua fala em uma forma de expressão na qual só o não-dito contém o que realmente lhe importa. Esse nãodito toma corpo e ganha significação ao emergir sutilmente através de determinados vocábulos e expressões de que a personagem se vale, na tentativa de expor seu desejo: with my whole heart / every bone / every organ / nearly cried $^{2 l}$. Quer dizer, sob a agressão da voz do autoritarismo, outra voz faz silêncio para, então, se fazer linguagem (aqui, sob a forma das expressões mencionadas). Silêncio / linguagem que se faz particularmente pesada e trágica no momento da pergunta final do médico: Vicente, how did you know? ${ }^{22}$. Que fique o médico sem resposta. Seria preciso recontar-lhe uma vida. Então, entenderia.

A aceitação do autoritarismo observado em "A man told me the story of his life" encontra correspondência na aceitação do império da banalidade, da trivialidade e do mau gosto que caracterizam o problema central em "This is a story about my friend George, the toy inventor"23. Aqui a arte de George é rejeitada pela instituição e o artista conforma-se para que possa se preservar como membro de uma comunidade industrial.

Uma vez mais, o silêncio se faz nos interstícios existentes entre a fala conformada do artista e aquilo que ele é, revelação feita ao leitor através das vozes de outras personagens, que são caracterizadas como we e the family.

He had invented a pin ball machine. When we saw it, we said, George! This is not a pinball machine alone. This is the poem of a pinball machine, the essence made delicately concrete, and so forth (...).

It is certainly beautiful and stands so far ahead of its time that we were not surprised to learn it had been rejected. ${ }^{25}$

A palavra, desvinculada do compromisso com a empresa, soa livre na descrição da arte da personagem George feita por "we" e funciona como

11. PALEY, 1985. p.128. Em português: "(..) com todo o meu coração", "(...) caso osso, coda órgüo", "(...) quase chorou".

12. PALEY, 1985. p.130. Em português: "Vicente, como wocê ficau sobendo?"

23. PALEY, 1985. p. 147

24. PALEY, 1985. pp. 147, 148.

25. PALEY, 1985. p. 148. Em português: "Ele rinho inventado uma máquino de fliperama. Quondo nós a vimos, folamos: George Isto nãa é só uma móquino de fliperama. Isto ê un poemo de uma máquina de fliperama, a essência tarnada delicadamente concreta, e doí por diante.

E de fota linda e estó too o frente de sua época que nóo ficomos surpresos oo sober que ela fai recusada. contraponto ao silêncio obstinado que ele impõe a sua fala. Vê-se que o processo se inverte, uma vez que o usual seria termos uma configuração oposta, qual seja, aquela em que o silêncio seria o contraponto da palavra, ela, sim, focalizada como ponto principal de convergência. A inversão desses efeitos acentua a dramaticidade que a autora é capaz de imprimir à utilização desse recurso de linguagem.

Isso leva-nos a concluir que o título deste trabalho remete mais incisivamente à voz autoral que às vozes das personagens. É ela, Grace Paley, a sagaz tecedeira que vai fazendo a trama de sua escrita, utilizando as laçadas da palavra em constante jogo com os espaços do silêncio. Assim constrói personagens, assim mostra-as despojadas da palavra por força de um sistema, assim usa o silêncio, dando-lhe forma como opção de linguagem e construção de sentido para caracterizar um mundo às vezes sem linguagem e sem sentido. $\mathrm{E}$, assim, põe em contato a superfície da interioridade de um eu-individual com a superfície da exterioridade de um eu-social, produzindo um sistema sonoro vigoroso, ordenador de uma linguagem ao mesmo tempo econômica e de extrema expressividade.

Uma voz autoral que ressalta as limitações do ser no seu sofrimento ao lidar com as próprias emoções, que enfatiza vozes que permanecem basicamente mudas, promovendo um deslocamento de sentido da palavra para o silêncio.

Uma voz autoral que reconhece a impossibilidade da fala sob o efeito de formas várias de repressão e que convive com os limites da linguagem não se detendo neles, nem sendo detida por eles. Ao contrário, ultrapassa-os e, nesse salto para o outro lado da linha-limite, ao faltar-lhe chão aos pés, resolve habilmente o problema: mantendo potencialidades em levitação e palavras em suspensão. Transformando-as, enfim, em formas possíveis de comunicação, tornadas ainda mais concretas pelos enérgicos traços com que compõe seus textos curtos e lacunares, nos quais o silêncio se faz co-palavra, convergência de sentidos, presença dilacerante. 
This study attempts to demonstrate the ways through which the writing of Grace Paley, a contemporary American author, makes use of silence and of the unsaid to denounce and deconstruct false values upon which certain social structures have been established. KEY WORDS:

Grace Paley, silence, mask, voice

\section{PAUL AUSTER TOPÓGRAFO: 0 ESPAÇO URBANO CONTEMPORÂNEO}

Luis Alberto Brandão Santos

UFMG

\section{REFERENCIAS BIBLIOGRIFICAS:}

BAKHTIN, M.M. Speech genre ond ather essoys. Trod. Vern McGee. Texas: University of Texas Press, 1986

KEERKEGAARD, S. Feor ond hembling. Trad. H. V. Hong \& E. H. Hong. Princeton: Princeton Universily Press, 1983.

PALE, Grace. A man fold me he slory of his life . IN: Loler the some doy. New York Forror Straus Giroux, 1965, p. 129. "In this country, but in another longuage, my aunt refuses to mary the men everyone wonts her to". IN: Later the same

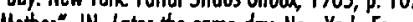

Mother. IN: Loter the same day. New York: Forrar Strous Giroux 1965 p. 111

_. "This is a story about my friend George, the toy imentor". IN: Loter the some doy. New York. Fanar Shrous Groux, 1965, p. 129.

\author{
He is alive, and therefore he is nothing \\ but what drowns in the fathomless hole \\ of his eye, \\ and what he sees \\ is all that he is not: a city \\ of the undeciphered \\ event, \\ and therefore a language of stones, \\ since he knows that for the whole of life \\ a stone \\ will give way to another stone \\ to make a wall \\ and that all these stones \\ will form the monstrous sum \\ of particulars.
}

Paul Auster, "Disappearances"

\section{RESUMO:}

As narrativas de Paul Auster são representações topográficas da cultura urbana contemporânea. Escrever é esboçar mapas dos espaços sociais, investigar a instabilidade desses mapas e a dimensão ficcional de tais espaços. PALAVRASCHAVE

Cultura urbana, espaços sociais, literatura contemporânea 